\title{
CREENCIA, ACTIVACIÓN Y COMUNIDADES CULTURALES: GESTINF, O LA PERTINENCIA DE UN CORPUS BASADO EN EL CONOCIMIENTO COMPARTIDO
}

\author{
Susana RodRÍGUEZ RoSIQUE \\ Universidad de Alicante (España)
}

\section{RESUMEN}

El objetivo de este trabajo es reivindicar la pertinencia del corpus GestINF como un material orientado para evaluar la relación entre la configuración informativa y la estructuración lingüística, y analizar la postura discursiva del hablante ante una situación informativa concreta. Así, se sitúa en el mapa de los corpus en español, se justifica la hipótesis teórica que subyace a la creación del corpus, y se descubren las claves que desvelan el proceso de su gestación. Para demostrar la simbiosis entre configuración informativa y estructuración lingüística, se estudian algunos fenómenos: por un lado, estrategias tradicionalmente vinculadas con la estructura informativa -como la distribución de los demostrativos o la focalización- se revisan desde una óptica distinta; por otro, se abordan algunos fenómenos que hasta ahora no se habían relacionado con la configuración informativa, como la rentabilidad interactiva de las interrogativas o la creación de material gramatical.

PALABRAS ClaVE: corpus GestINF; conocimiento compartido; miratividad; intersubjetividad; demostrativos; focalización; interrogativas; construccionalización.

\section{ABSTRACT}

The aim of this paper is to highlight the relevance of the GestINF corpus as a material oriented to analyze the relation between informational configuration and linguistic structure as well as to evaluate the speaker's discursive stance towards a certain informational situation. Firstly, the GestINF corpus is situated within the map of the Spanish corpora, the theoretical hypothesis supporting it is justified, and the keys explaining its development are revealed. Secondly, some phenomena are studied in order to show the symbiosis between informational configuration and linguistic structure: on the one hand, certain strategies traditionally linked to information structure are revised from a different angle, such as focalization or the distribution of demonstratives; on the other hand, certain issues that have 
not been related to informational configuration until now are approached, such as the interactive power of interrogative sentences or the creation of grammatical material.

KEYWORDS: GestINF corpus; shared knowledge; mirativity; intersubjectivity; demonstratives; focalization; interrogative sentences; constructionalization.

Fecha de recepción: 16/09/2020

Fecha de aceptación: 09/10/2020

Fecha de la versión definitiva: 10/11/2020

\section{Pero... ¿DE VERdad ES NeCESARio otro Corpus?}

El objetivo de este trabajo es presentar las claves que explican el diseño del corpus GestINF y reivindicar su pertinencia para el análisis de la relación entre gramática y configuración informativa. El corpus GestINF surge al amparo del proyecto «Gestión de la información y estructuración lingüística: Explicaciones y Aplicaciones» ${ }^{1}$, que tiene como uno de sus objetivos prácticos la creación de un corpus en el que se acote el conocimiento compartido de sus participantes con el fin de analizar, de la manera más precisa posible, la relación bidireccional que existe entre la configuración informativa y la estructuración lingüística (Rodríguez Rosique 2019a: 101124; Rodríguez Rosique y Antolí Martínez 2020)².

Ante este propósito, una de las preguntas más acuciantes que se plantean es la de si resulta necesario recopilar un nuevo corpus. De acuerdo con el estudio panorámico de Briz y Albelda (2009: 165), aunque las tareas vinculadas con la creación de corpus en español están aumentando en los últimos años, el número es todavía escaso, en la medida en que aún resulta posible realizar un mapeo como el que se ofrece en el trabajo que recogen los autores.

Para Rojo (2016: 285), un corpus está constituido por un conjunto de textos que han de reunir las siguientes características:

a) deben ser naturales -no pueden haber sido expresamente creados para su incorporación al corpus-;

${ }^{1}$ Este trabajo forma parte de los resultados del proyecto «Gestión de la información y estructuración lingüística: Explicaciones y Aplicaciones» (FFI2017-85441-R). Quiero agradecer los comentarios de los dos revisores anónimos que han llevado a cabo la evaluación del artículo.

${ }^{2}$ El objetivo principal de analizar la interacción entre configuración informativa y estructuración lingüística se concreta en una serie de líneas de actuación, tanto de carácter teórico como de naturaleza aplicada. Para una presentación de los principales caminos que concretan este objetivo, puede verse Rodríguez Rosique (2019b). 
b) deben estar en formato electrónico -pues solo así se puede recuperar la información-;

c) deben ser representativos -han de constituir muestras que den cuenta de la variedad de la que proceden-; y

d) deben permitir el estudio científico -lo que supone incluir información gramatical, léxica y pragmática-.

En este sentido, en opinión de Rojo, a todo corpus subyace un diseño en su configuración, lo que los diferencia de los archivos (o conjuntos de textos integrados en un formato único que no obedecen a un propósito concreto). Por su parte, Briz y Albelda (2009: 165-166) definen los corpus como conjuntos de muestras de lengua recogidas en su contexto natural, lo que los opone a las bases de datos (o selección de textos extraídos de distintas publicaciones que se han reunido con otros fines). Igualmente, estos autores reconocen que la carta de naturaleza del corpus reside en la voluntad del lingüista de seleccionar unas determinadas muestras a partir de un plan previo.

En el caso concreto de los corpus de lengua hablada tomados en contextos naturales, Briz y Albelda (2009: 168) diferencian entre entrevistas y conversaciones, según el grado de espontaneidad que presenten. Las entrevistas se llevan a cabo, prototípicamente, entre dos personas: una de ellas suele dirigir el diálogo; $y$, aunque pueden adquirir cierto nivel de espontaneidad, normalmente prima en ellas un acuerdo transaccional, pues el informante acepta que su testimonio lingüístico va a ser registrado. Entre los corpus que siguen este modelo ${ }^{3}$, destaca el macroproyecto PRESEEA (<https://preseea.linguas.net/Corpus.aspx $>$ ), cuyo objetivo es construir un gran corpus oral que sea lingüísticamente representativo y que funcione como una muestra del habla de distintas ciudades en el mundo hispánico (Moreno Fernández 2005: 126). También siguen fundamentalmente el esquema de entrevista otros corpus centrados en determinadas zonas concretas, como el Corpus del habla de Almería (<http://www.grupoilse.org/ corpus.asp $>$ ) o el Corpus del habla de Sevilla (Bañón, Cortés y Carbonero 2005), el estudio sociolingüístico de la ciudad de Granada (Moya Corral y Villena Ponsoda 2005), y el Corpus de español oral en Bilbao (Etxebarria y Vila 2005), por citar solo algunos ejemplos representativos de distintos lugares peninsulares. Con respecto a los corpus de conversaciones, Briz y

${ }^{3}$ El propósito de esta introducción no es ofrecer un inventario de los principales corpus del español, ni elaborar una propuesta teórica desde la perspectiva de la lingüística de corpus, sino señalar algunos ejemplos que funcionen como coordenadas para situar entre ellos al corpus GestINF. Para una presentación exhaustiva de los principales corpus del español, véanse el mencionado estudio panorámico de Briz y Albelda (2009), el también citado trabajo de Rojo (2016) o, desde una perspectiva diacrónica, la revisión de Rodríguez Puente (2018). 
Albelda (2009) los definen por su espontaneidad y naturalidad, y añaden que estos corpus exhiben una serie de rasgos vinculados con la variedad situacional, como el distinto número de hablantes, la heterogeneidad e imprevisibilidad en cuestiones de edad, sexo, nivel sociocultural o relación entre los interlocutores, la variedad temática, etc. Entre los corpus de conversaciones más representativos del español actual se encuentran el COLA (<https://cola.w.uib.no/>), dirigido por Annette Myre y centrado en la variedad del lenguaje adolescente; el Corpus conversacional de Barcelona y su área metropolitana (Vila 2001; Etxebarria y Vila 2005); el Corpus Val.Es.Co. (<www.valesco.es >) (Briz y Grupo Val.Es.Co. 2002; Ruiz Gurillo y Pons Bordería 2005); o los dos corpus elaborados en Alicante (Azorín 2005): el ALCORE (Azorín 2002) y el COVJA (Azorín y Jiménez Ruiz 1997), este último centrado también en la variedad juvenil.

Una vez esbozado este mapa de coordenadas, sostenido por algunos puntales básicos de la lingüística de corpus en español, cabría preguntarse qué lugar ocupa en él el corpus planificado por el proyecto GestINF. En este sentido, las características que definen el corpus están determinadas por el objetivo principal que persigue el proyecto: contar con un material orientado que permita analizar la relación bidireccional entre configuración informativa y estructuración lingüística. Este propósito exige, por un lado, que se trate de un corpus pequeño; en concreto, circunscrito a las distintas comunidades anidadas en la Universidad de Alicante. Por otro lado, la necesidad inicial determina también la condición híbrida del corpus, a medio camino entre lo espontáneo y lo guiado. En efecto, frente a las entrevistas, el corpus GestINF se presenta como un conjunto de conversaciones que favorecen la naturalidad; sobre todo, por lo que respecta a la dinámica, a las estrategias y a los roles conversacionales que eligen libremente los hablantes. No obstante, tanto la selección de informantes -basada en perfiles que cruzaran distintas porciones de conocimiento compartido anidadas en los diferentes roles que configuran la esfera universitariacomo los temas que se proporcionaron previamente a los participantes -y que se presentaban como puntos de partida o desencadenantes de la conversación- imponen cierto carácter guiado a la interacción.

Para explicar cómo funciona el corpus GestINF, en qué se basa, y qué fenómenos permite analizar, este trabajo se ha estructurado de la siguiente manera: en la segunda sección se expone el marco teórico del que parte la idea de elaborar un corpus -en concreto, qué se entiende por conocimiento compartido y cómo se ha abordado desde distintas perspectivas-; en la tercera sección se presenta el corpus -esto es, se justifica cómo se ha diseñado (lo que incluye la preparación de materiales, la selección de informantes, la manera en la que se ha recopilado y el tratamiento de los textos) y se exponen los resultados obtenidos-; en la cuarta sección se 
ofrece un catálogo de algunos fenómenos que permite estudiar el corpus -desde aquellos habitualmente vinculados con el conocimiento compartido (como el funcionamiento de los demostrativos o del foco informativo) hasta otros habitualmente menos tratados desde esta perspectiva (como la rentabilidad interactiva de la interrogación o la creación de construcciones nuevas que se explican en buena medida a partir de herramientas basadas en la configuración informativa)-; finalmente, la quinta sección presenta las conclusiones más relevantes del estudio.

\section{LA SOMBRA DEL SABER ES ALARGADA}

Cualquier tipo de discurso constituye una actividad conjunta (Levinson 1979; Clark 1996: 17-25), como también lo son bailar un vals, hacer el amor o interpretar un dúo en el piano. Su naturaleza exige, al menos, dos participantes, que pueden ser reales o imaginarios, instituciones o individuos, y que deben realizar algo más que acciones autónomas; en concreto, deben llevar a cabo acciones conjuntas, que exigen la coordinación de acciones individuales. El entorno comunicativo más básico en el que se lleva a cabo la interacción, como tipo de actividad conjunta, es la conversación, que adquiere, por tanto, un estatus especial (Fillmore 1981; Chafe 1994: 41; Clark 1996: 8-11). Existen diversas razones que justifican su consideración como entorno básico: es universal, pues se encuentra en todas las sociedades humanas; no requiere habilidades especiales ni ningún tipo de instrucción, a diferencia de lo que ocurre con otros tipos de discurso -como impartir una conferencia, pronunciar un sermón o contar un chiste-; y es el entorno natural en el que los niños adquieren la lengua. La conversación se define como un tipo de discurso configurado por la sucesión y alternancia de turnos de habla ocupados por diferentes hablantes (Briz y Grupo Val.Es.Co. 2003, 2014), y exhibe un conjunto de características que la perfilan como tipo de discurso (Briz 2000: 51; Hidalgo 2002: 9-10; Portolés 2004: 68):

a) se lleva a cabo a través del canal oral, lo que provoca evanescencia, falta de transportabilidad y simultaneidad, pero también espontaneidad (Chafe 1994: 42-45; Clark 1996: 9-10);

b) se caracteriza por la inmediatez (aquí, ahora, cara a cara y de forma instantánea);

c) es de naturaleza dialogal -pues surge de la sucesión de distintas intervenciones- y dinámica -ya que exige el cambio constante de los papeles de hablante y destinatario-, lo que la convierte en la muestra por antonomasia de la interacción (Chafe 1994: 44-45); 
d) refleja el esfuerzo cooperativo del hablante y del destinatario en la construcción del significado. A partir de aquí, cualquier otro tipo de discurso se considera una desviación (Fillmore 1981: 152).

Toda actividad conjunta, como la que implica la interacción entre un hablante y su destinatario, impone un requisito para que se pueda llevar a cabo: los participantes han de poseer algún tipo de conocimiento compartido antes de verse envueltos en el desarrollo de la actividad. En efecto, cuando la gente toma partido en las conversaciones, trae consigo una serie de conocimientos, creencias, asunciones, o cualquier otro tipo de información que Stalnaker (1978) denominó Common Ground ['contexto común']. El conocimiento compartido de dos personas es la suma de sus suposiciones, creencias y conocimientos mutuos (Clark 1996: 93). Esta información no aparece sin más; por el contrario, es necesario establecerla con cada persona con la que interactuamos: el hablante se ve en la necesidad constante de aventurar hipótesis sobre lo que él cree que constituye información ya asumida por su destinatario -es lo que se conoce como la hipótesis de la pregunta inicial (Gutiérrez Ordóñez 1997: 26)-.

Existen dos tipos de fuentes que alimentan el conocimiento compartido: las comunitarias y las personales. El conocimiento compartido comunitario se basa en la existencia de comunidades culturales (Clark 1996: 101-112). A menudo categorizamos a nuestros destinatarios por su nacionalidad, lengua, profesión, aficiones, religión, etc., para poder inferir lo que saben, creen o asumen. Una comunidad cultural es, pues, un grupo de gente con experiencias compartidas de las que otras comunidades carecen. Entre la información que forma parte de ese conocimiento compartido se encuentra aquella que tenemos por el mero hecho de ser seres humanos: todos experimentamos las mismas sensaciones. A partir de aquí, cada comunidad cultural puede desarrollar un léxico especializado, lo que permite aislar terminologías, argots, jergas o nomenclaturas. También se encontraría entre esta información el conocimiento de determinados hechos culturales, normas de comportamiento, convenciones propias de cada comunidad; el manejo de habilidades o procedimientos; y la posesión de creencias, asunciones o incluso experiencias inefables. Las comunidades culturales se relacionan mediante anidamientos, por lo que cada uno de nosotros pertenece, de forma simultánea, a varias de ellas; en concreto, yo estaría adscrita a la comunidad de los españoles, de las mujeres, de los lingüistas, etc. La tabla 1 recoge algunos ejemplos de comunidades culturales.

El conocimiento compartido personal, por su parte, se basa en experiencias personales conjuntas, entre las que se pueden diferenciar dos tipos: experiencias perceptivas conjuntas y acciones conjuntas (Clark 1996: 112116). Si el conocimiento compartido comunitario define comunidades 
TABLA 1. Ejemplos de conocimiento compartido comunitario, basado en comunidades culturales (Clark 1996: 103)

\begin{tabular}{lll}
\hline $\begin{array}{c}\text { Bases para } \\
\text { la experiencia }\end{array}$ & \multicolumn{1}{c}{ Ejemplos de comunidad } & \multicolumn{1}{c}{ Ejemplos de experiencias } \\
\hline Nacionalidad & Americana, canadiense, española & $\begin{array}{l}\text { Prácticas culturales de la nación, } \\
\text { instituciones }\end{array}$ \\
\hline $\begin{array}{l}\text { Formación } \\
\text { académica }\end{array}$ & $\begin{array}{l}\text { Estudiantes universitarios, } \\
\text { estudiantes de Derecho, estudiantes } \\
\text { de secundaria }\end{array}$ & $\begin{array}{l}\text { Contenidos específicos, } \\
\text { competencias formativas }\end{array}$ \\
\hline Etnia & Negros, hispanos, afroamericanos & $\begin{array}{l}\text { Aspectos vinculados con la } \\
\text { herencia cultural, experiencias } \\
\text { y prácticas propias de la etnia }\end{array}$ \\
\hline Política & $\begin{array}{l}\text { Demócratas, liberales, socialistas, } \\
\text { marxistas }\end{array}$ & $\begin{array}{l}\text { Claves políticas, valores, figuras } \\
\text { políticas relevantes }\end{array}$ \\
\hline Subcultura & $\begin{array}{l}\text { Estrellas del rock, bandas callejeras, } \\
\text { drogodependientes }\end{array}$ & $\begin{array}{l}\text { Códigos underground, jergas, } \\
\text { saber hacer }\end{array}$ \\
\hline \multirow{2}{*}{ Género } & Hombres, mujeres, transexuales & $\begin{array}{l}\text { Funciones corporales, } \\
\text { costumbres sociales propias } \\
\text { de cada género }\end{array}$ \\
\hline
\end{tabular}

culturales, el conocimiento compartido personal se define por el parámetro de la familiaridad: alguien nos resultará más o menos cercano en función de nuestro historial de experiencias personales conjuntas.

\subsection{La labor de la conciencia}

A pesar del conocimiento de fondo que gobierna la interacción, desde una perspectiva cognitiva se asume que la mente de un individuo solo puede centrarse en un pequeño segmento de todo lo que sabe (Chafe 1994). Este proceso de restricción se lleva cabo mediante la labor de la conciencia. En opinión de Chafe, la limitación de la conciencia determina el alcance de aquello en lo que nos podemos centrar. Por ejemplo, no podemos pensar en un lapso temporal amplio (mis años de instituto) o en una persona (mi padre) de una forma que no sea progresiva: puedo pensar en un lugar, un momento o una circunstancia de mis años como estudiante; o puedo perfilar una acción o una imagen de mi padre. En la propuesta de Chafe (1994: 53-56), según el estado focal, periférico o inconsciente de una idea en la conciencia, se puede decir que está activa, semiactiva o inactiva. El autor 
reconoce que, intuitivamente, se suele asumir que una idea nueva es aquella previamente desconocida por el destinatario. Sin embargo, esta concepción plantea un problema al explicar la diferencia entre a. Anoche hablé con Ana y b. Anoche hablé con ella. En efecto, para que el hablante utilice Ana debe asumir que su destinatario conoce el referente, de lo contrario habría utilizado una chica, una amiga, etc. Sin embargo, para explicar la distinción entre $a$ y $b$ lo importante no es si el destinatario conoce o no el referente, sino si la idea de esta persona estaba previamente inactiva en la conciencia del destinatario y se activa en ese punto de la conversación gracias al enunciado del hablante; o si ya estaba previamente activada y con el enunciado se mantiene en el foco de la conciencia.

Por tanto, parece que el concepto de información conocida puede relacionarse con dos parámetros, como plantea Prince (1981: 228-230): con el conocimiento compartido y con la saliencia cognitiva. La presuposición parece seguir ligada al concepto de verdad -es decir, es una proposición que el hablante y el destinatario asumen (o están dispuestos a asumir -Lewis 1979-) como verdadera, por lo que estaría vinculada a la información conocida en términos de conocimiento compartido-; por el contrario, una proposición activada no tiene por qué ser cierta (Dryer 1996).

El proceso de activación de la información no se entiende en términos binarios, sino que funciona más bien como un continuo (Dryer 1996), en el que uno de los extremos estaría ocupado por la información máximamente activada -o foco de activación- y el extremo contrario incluiría la información no activada. En el medio se encontraría tanto la información accesible -esto es, aquella que no ha sido activada como tal, pero que está vinculada con información activada gracias a relaciones de discurso (Duque 2016: 21-45) - como la información desactivada -es decir, aquella que estuvo activada, pero que ha ido perdiendo progresivamente su prominencia-.

\subsection{Evidencialidad y conocimiento compartido}

Desde la perspectiva de la estructura informativa del discurso, un aspecto fundamental lo ha constituido la diferencia entre información conocida e información activada. No obstante, el concepto de información conocida o conocimiento compartido ha sido también aprovechado desde otros puntos de vista.

En su concepción clásica, la evidencialidad es una categoría lingüística vinculada con la fuente de información y con el modo de acceso a la misma (Willet 1988; Aikhenvald 2004). Así, el enunciado He visto a María salir del supermercado nos informa de que el hablante ha accedido a la información de forma directa -en concreto, a través de la percepción-; el enunciado 
María habrá salido a comprar nos dice que el hablante ha accedido a la información de manera indirecta -a través de una inferencia-; y Juan me ha dicho que María ha salido a comprar expresa que el hablante accede a la información también de manera indirecta -aunque esta vez a través de un tercero-. De acuerdo con algunos autores, sin embargo, esta concepción estándar de la evidencialidad plantea problemas.

Para Bermúdez (2005: 14-17), la noción clásica de evidencialidad deja fuera del esquema valores claramente relacionados con la fuente de información, como el conocimiento compartido. Para solucionarlo, el autor propone añadir una nueva dimensión a la descripción del dominio evidencial, como refleja la figura 1: un continuo que discurra entre el acceso privativo a la información -o restringido al hablante- y el acceso irrestricto o universal; en el punto medio de este continuo se situaría la información que se encuentra accesible solo para el hablante y el destinatario.

FIgURA 1. Revisión del dominio evidencial (Bermúdez 2005: 17)

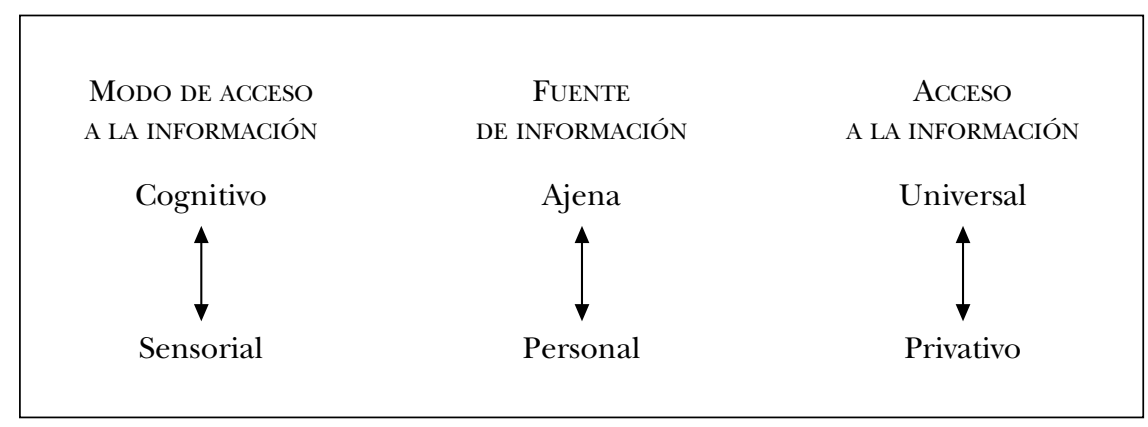

La propuesta de Bermúdez, sin embargo, se enfrenta a dos problemas: el primero afecta a la manera en la que la relación entre información conocida e información activada se integra en este modelo, como se ha discutido anteriormente; el segundo tiene que ver con la relación entre los tres parámetros -en concreto, con si gozan del mismo estatuto-.

Para responder a este segundo problema se puede acudir al concepto de (inter)subjetividad de Nuyts (2001a, 2001b, 2012). Para Nuyts (2001a: 3338), la (inter) subjetividad surge como una revisión crítica de la distinción establecida por Lyons (1977: 797-800) entre una modalidad epistémica subjetiva y una modalidad epistémica objetiva. Nuyts reinterpreta esta distinción en términos de calidad de la evidencia que tiene el hablante para llevar a cabo una evaluación epistémica. Se extiende a lo largo de un continuo, en el que uno de los polos indicaría que solo el hablante tiene acceso a la evidencia, y, por tanto, saca sus propias conclusiones de ello (subjetividad); 
el polo opuesto indicaría que la evidencia es conocida -o accesible- por un grupo más amplio de gente (intersubjetividad). A partir de aquí, cuando el hablante presenta una información como subjetiva, asume una responsabilidad personal en su evaluación epistémica; cuando una información se presenta como intersubjetiva, la responsabilidad es compartida. Nuyts (2012) añade que, por una parte, se espera una marcación subjetiva cuando el evaluador cree que no debería implicar a nadie más en su evaluación modal -bien porque no sabe la postura de los otros, o bien porque su postura está en clara oposición con la de los otros-; por otra parte, se espera una marcación intersubjetiva cuando el evaluador quiere indicar, contra el destinatario, que su postura no es aislada ni estrictamente personal o arbitraria, o cuando el evaluador asume que él y su destinatario están de acuerdo y quiere expresarlo. En su trabajo de 2012, el autor reconsidera el estatuto de la (inter)subjetividad, y ya no la concibe como un parámetro de la evidencialidad, sino como una categoría independiente que se sitúa frente a la miratividad. En efecto, para Nuyts (2012), la (inter) subjetividad está vinculada con la existencia de un evaluador y se utiliza como herramienta discursiva para negociar las respectivas posturas en la interacción conversacional.

\subsection{Información nueva y miratividad}

Si la información conocida se ha asociado con la evidencialidad, la información nueva se ha vinculado con la miratividad (DeLancey 1997). En efecto, la miratividad es una categoría relativamente reciente, que se vincula con la sorpresa y la reacción de «mente no preparada» del hablante (Aksu-Koç y Slobin 1986) ante una determinada información. DeLancey (1997, 2001) relaciona la miratividad con la tendencia general de las lenguas a distinguir entre la información sobre el mundo que forma parte integrada del conocimiento del hablante, y la información que no forma parte de la estructura general del conocimiento del hablante. Parece claro, por tanto, que la miratividad exhibe dos componentes básicos (Rodríguez Rosique 2019: 196-201): un componente evaluativo, vinculado con la sorpresa; y un componente informativo, relacionado con la información nueva. No obstante, el papel que ocupa la información nueva en el concepto de miratividad no está exento de controversia, como han propuesto algunos estudios recientes. Desde el punto de vista de la estructura informativa del discurso, el estatuto de «nuevo» se evalúa siempre desde la perspectiva del destinatario. Sin embargo, Hengeveld y Olbertz (2012) proponen que la información que desencadena la sorpresa puede ser nueva para el hablante o nueva para el destinatario; asimismo, Aikhenvald (2012) añade que la información puede ser nueva para el hablante, nueva para el desti- 
natario o nueva para el personaje principal de una historia; $y$, finalmente, Peterson (2013) concluye que la información nueva no es requisito suficiente para hablar de miratividad.

\section{LA COCINA DEL GESTINF}

$\mathrm{Al}$ amparo de la encrucijada marcada por los principales componentes teóricos que se han descrito en el apartado anterior, en el diseño del corpus GestINF existe un precepto fundamental: ajustar de la forma más precisa posible las diversas coordenadas que nos pueden ayudar a determinar la configuración informativa que está detrás de cualquier intercambio comunicativo, desde los distintos niveles de anidamiento generados por el conocimiento compartido comunitario y personal (Clark 1996) hasta los diferentes de grados de activación informativa (Chafe 1994; Dryer 1996).

\subsection{Preparación del corpus}

En consonancia con ese precepto inicial, el objetivo más inmediato del corpus era ofrecer un retrato robot de la configuración informativa de cada interacción a partir de la determinación de los nidos de conocimiento compartido más prominentes a los que hubiesen estado expuestos los participantes de cada conversación, así como de la información que se hubiese ido activando conforme la interacción progresaba. Asimismo, se pretendía que los participantes representaran arquetipos de la comunidad universitaria. Por ello, se diseñaron interacciones entre grupos de unas cuatro personas que pertenecieran a distintos sectores de la universidad (especialmente, estudiantes, profesores y personal de administración y servicios). También se intentó que alguno de los participantes ocupara algún cargo sindical o de política universitaria.

En cuanto al proceso de reclutamiento, en el caso de los estudiantes se hacía un llamamiento en clase para que las personas interesadas se pusieran en contacto con la coordinadora del proyecto y les explicara en qué consistiría su participación. Todos los estudiantes que participaban en una interacción pertenecían al mismo grado y al mismo curso; es decir, todos eran compañeros de clase. En el caso de los otros colectivos (PDI y personal de administración y servicios), se contactaba con un miembro -normalmente, alguien conocido por un investigador del proyecto, y que se esperara que estuviera dispuesto a participar-y se le encargaba la tarea de reclutar a dos o tres compañeros más que quisieran contribuir al proyecto como informantes. Todos los participantes de cada grupo se conocían, por tanto, antes de la interacción. 
Para poder controlar mejor el tipo de conocimiento compartido con el que los participantes accedían a la interacción, a cada grupo se le proporcionarían dos documentos: uno de ellos estaría vinculado con su formación, especialización o área de trabajo; el otro versaría sobre un tema de actualidad. Asimismo, para registrar toda aquella información que se pudiera generar en la interacción, se decidió que las conversaciones fueran grabadas en formato audiovisual. El lugar para las grabaciones debería ser un entorno neutro que, además, asegurara una buena calidad de imagen y sonido para el posterior tratamiento audiovisual del corpus; por ello, se optó por el plató que el Gabinete de Imagen tiene en el campus de la Universidad de Alicante, y se contó con el personal de esta unidad para llevar a cabo las grabaciones. Igualmente, se fijó un tiempo semejante para todas las interacciones (unos cuarenta minutos), aunque los participantes no conocían con antelación durante cuánto tiempo se extendería la grabación.

A todas las personas que intervienen en las conversaciones se les informó de los detalles del proyecto y del uso que se haría de las grabaciones (estarían disponibles en la página del proyecto y se utilizarían en artículos y textos de investigación y divulgación científica). Todos ellos manifestaron su acuerdo y firmaron un contrato de cesión de derechos de imagen y contenidos ${ }^{4}$.

Como se ha comentado, las grabaciones se llevaron a cabo en la Universidad de Alicante, y todas las interacciones se desarrollaron en castellano.

\subsection{Configuración de materiales}

El proyecto cuenta actualmente con ocho conversaciones en formato audiovisual. La primera conversación está protagonizada por estudiantes (dos chicos y dos chicas) del Grado en Estudios Ingleses de la Universidad de Alicante, quienes recibieron, unos días antes de la grabación, dos textos que sirvieran como desencadenantes para iniciar la interacción: uno de ellos trataba la fusión de las redes sociales Facebook, Instagram y WhatsApp; el otro estaba relacionado con la celebración del Bloomsday.

En la segunda conversación participaron cuatro trabajadores de administración y servicios; en concreto, dos mujeres de la secretaría administrativa de la Facultad de Filosofía y Letras de la Universidad de Alicante, y dos hombres de la secretaría administrativa del Departamento de Filología

${ }^{4}$ El contrato de cesión de derechos que los participantes firmaron responde al modelo de contrato que la Universidad de Alicante tiene para cesión de derechos de imagen y contenidos, y puede consultarse en la siguiente dirección: <https://si.ua.es/es/vertice/contratosde-cesion-de-derechos-de-imagen-y-autor.html>. 
Española, Lingüística General y Teoría de la Literatura. A estos participantes se les entregaron también dos textos unos días antes de la interacción: uno que abordaba la relación del cine con las plataformas de streaming, como Netflix o HBO; y otro sobre la manera en la que el Brexit podría afectar a la movilidad de estudiantes Erasmus.

En la tercera conversación intervinieron profesores de los distintos grados de Filología de la Universidad de Alicante que, a su vez, eran miembros del equipo decanal de la Facultad de Filosofía y Letras. De nuevo, participaron dos mujeres y dos hombres, y todos ellos recibieron dos textos: un artículo de opinión sobre el futuro de las Humanidades; y un documento de trabajo que estudiaba la posibilidad de que los estudiantes de la Facultad cursaran una doble titulación de forma simultánea.

La cuarta conversación está protagonizada también por estudiantes, esta vez del Grado en Español de la Universidad de Alicante. En esta ocasión intervinieron cuatro chicas, quienes recibieron dos textos antes de la interacción: uno de ellos abordaba la forma en la que su generación contemplaba las elecciones generales de 2019, que estaban a punto de celebrarse en ese momento; el otro comentaba la polémica desencadenada por una respuesta de la Real Academia de la Lengua Española ante una consulta en la red social Twitter vinculada con el género de los adjetivos.

La quinta conversación volvía a tener como protagonistas a personal de administración y servicios; esta vez a trabajadores de la red de bibliotecas de la Universidad de Alicante. En ella intervinieron dos hombres y dos mujeres, que también recibieron dos textos que pudieran actuar como desencadenantes de la interacción: el primero presentaba la filosofía del orden de la youtuber Mari Kondo -que, entre otras cosas, prohíbe tener más de treinta libros en casa-; el segundo versaba sobre el silencio en las bibliotecas.

La sexta conversación es la última en la que participan estudiantes; en este caso, pertenecientes al Grado en Traducción e Interpretación de la Universidad de Alicante. En ella intervinieron tres chicas y un chico. Como desencadenantes de la interacción, de nuevo se les habían proporcionado dos textos: uno sobre la polémica desatada por la celebración del festival Eurovisión 2019 en Israel ${ }^{5}$; y otro sobre el valor de las traducciones.

La séptima conversación está protagonizada por profesores del Grado en Geografía y Ordenación del Territorio de la Universidad de Alicante, que son también miembros del equipo docente del Máster en Desarrollo

\footnotetext{
${ }^{5}$ La polémica se basaba en el hecho de que un festival de música internacional concebido en torno a cierto espíritu de paz y unidad se celebrara en un país marcado por el conflicto, la desunión y la opresión hacia el pueblo palestino, como se comenta en el texto desencadenante, firmado por Mikel Ayestarán y publicado en La Voz de Galicia (07/05/2019).
} 
Local e Innovación Territorial de la UA. Los participantes -dos hombres y dos mujeres- habían recibido dos textos antes de la interacción: el de tema general versaba sobre las repercusiones tributarias de los regalos de boda (la conversación se grabó durante el período habilitado por el Gobierno para que los españoles presentaran su Declaración de Renta); el específico abordaba el tema de la gentrificación.

Por último, la octava conversación tiene como protagonistas a personal de servicios de la Universidad de Alicante; en concreto, a dos mujeres que trabajan en el servicio de limpieza y a dos hombres que pertenecen al servicio de mantenimiento. Unos días antes de la grabación, los participantes habían recibido también dos textos: el primero estaba vinculado con una ley que había entrado en vigor en 2019 y que obligaba a las empresas a registrar la jornada de sus trabajadores; el segundo era sobre las marcas blancas.

En definitiva, el proyecto cuenta actualmente con 8 conversaciones, de unos cuarenta minutos cada una, en las que han participado 32 informantes, como se resume en la tabla $2^{6}$, en la página siguiente.

Las grabaciones fueron subidas a YouTube y se hizo una primera transcripción manual (regular, en formato de escritura y con ortografía normalizada) para contar con un «texto» inicial ${ }^{7}$. Desde la Biblioteca Virtual Miguel de Cervantes se desarrolló un modelo para sincronizar múltiples vídeos (cada grabación contaba con tres planos) y para sincronizar vídeos y texto $^{8}$. De manera paralela, desde el proyecto se transcriben conversacionalmente las interacciones. Para la transcripción conversacional, se ha seguido un modelo estandarizado, como el que proponen y aplican, por ejemplo, Azorín (2002), Briz y Grupo Val.Es.Co. (2002) o Auer, CouperKuhlen et alii (2011).

El corpus estará albergado en el portal Proyecto GestINF, dentro de la Biblioteca Virtual Miguel de Cervantes, y será de acceso libre para cualquier investigador. La manera en la que el usuario accederá a los materiales que ofrece el corpus se observa en la Imagen 1. En concreto, cada conversación

${ }^{6}$ Dadas las limitaciones temporales del proyecto y el trabajo que exigen las tareas de tratamiento audiovisual, análisis y transcripción conversacional, y análisis lingüístico, estas 8 conversaciones constituirían una primera fase de recogida. Se espera solicitar una ampliación del proyecto para aumentar el número de conversaciones y completar las muestras con respecto a algunos parámetros de descripción: se han registrado interacciones en igualdad de género e interacciones con predominio de mujeres; faltarían, en este sentido, interacciones con predominio de hombres.

${ }^{7}$ Esta primera transcripción será la base para la realización de búsquedas, y sobre ella se hará el etiquetado. El objetivo es que esté sincronizada con los vídeos y con el texto de la transcripción conversacional.

${ }^{8}$ Esta forma de operar nos ha permitido secuenciar el volumen de trabajo. 
TABLA 2. Resumen conversaciones GestINF

\begin{tabular}{|c|c|c|c|}
\hline Conversación & Participantes & Colectivo & Temas desencadenantes \\
\hline Conversación 1 & $\begin{array}{l}2 \text { chicos } \\
2 \text { chicas }\end{array}$ & Estudiantes & $\begin{array}{l}\text {-Redes sociales } \\
\text {-Bloomsday }\end{array}$ \\
\hline Conversación 2 & $\begin{array}{l}2 \text { hombres } \\
2 \text { mujeres }\end{array}$ & $\begin{array}{l}\text { Personal de } \\
\text { administración }\end{array}$ & $\begin{array}{l}\text {-Cine y plataformas } \\
\text { de streaming } \\
\text {-Brexit y Erasmus }\end{array}$ \\
\hline Conversación 3 & $\begin{array}{l}2 \text { mujeres } \\
2 \text { hombres }\end{array}$ & PDI & $\begin{array}{l}\text {-Futuro de las Humanidades } \\
\text {-Titulaciones de doble grado }\end{array}$ \\
\hline Conversación 4 & 4 chicas & Estudiantes & $\begin{array}{l}\text {-Elecciones generales } \\
\text { de } 2019 \\
\text {-RAE y Twitter }\end{array}$ \\
\hline Conversación 5 & $\begin{array}{l}2 \text { hombres } \\
2 \text { mujeres }\end{array}$ & $\begin{array}{l}\text { Personal de } \\
\text { administración }\end{array}$ & $\begin{array}{l}\text {-Filosofía del orden de Marie } \\
\text { Kondo } \\
\text {-Silencio en las bibliotecas }\end{array}$ \\
\hline Conversación 6 & $\begin{array}{l}3 \text { chicas } \\
1 \text { chico }\end{array}$ & Estudiantes & $\begin{array}{l}\text {-Eurovisión } 2019 \\
\text {-Valor de las traducciones }\end{array}$ \\
\hline Conversación 7 & $\begin{array}{l}2 \text { hombres } \\
2 \text { mujeres }\end{array}$ & PDI & $\begin{array}{l}\text {-Regalos y repercusión } \\
\text { tributaria } \\
\text {-Gentrificación }\end{array}$ \\
\hline Conversación 8 & $\begin{array}{l}2 \text { mujeres } \\
2 \text { hombres }\end{array}$ & $\begin{array}{l}\text { Personal } \\
\text { de servicios }\end{array}$ & $\begin{array}{l}\text {-Registro de jornada laboral } \\
\text {-Marcas blancas }\end{array}$ \\
\hline
\end{tabular}

viene precedida por un pequeño texto de presentación que recoge información sobre la filiación del grupo (metadatos). Asimismo, en la esquina derecha aparecen dos enlaces que permitirán acceder a los dos textos que se les proporcionaron a los participantes como desencadenantes de la interacción. La parte central de la pantalla la ocupa un plano general de la conversación, con un sistema de audio global. A la derecha se localizan dos pantallas laterales que ofrecen los planos cortos (dos participantes a la derecha y dos participantes a la izquierda), también con audios separados. Finalmente, en la parte inferior de la pantalla se incluye un cuadro de texto con la transcripción conversacional, que avanza simultáneamente conforme va progresando la conversación. 
IMAGEN 1. Corpus GestINF. Formato para el usuario

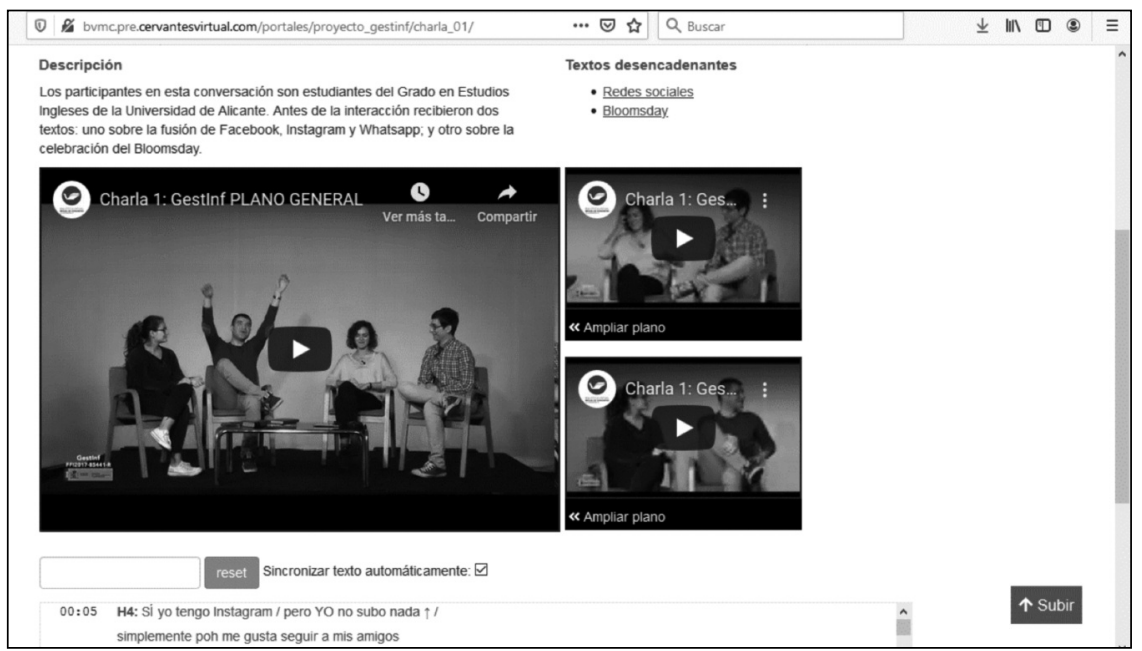

4. ¿NuEVOS ENFOQUES PARA VIEJOS PROBLEMAS O NUEVOS PROBLEMAS PARA VIEJOS ENFOQUES?

Como se ha planteado en la introducción, el objetivo que subyace al proyecto GestINF es determinar de qué manera la configuración informativa interactúa con la estructuración lingüística en un viaje de ida y vuelta: es decir, de qué forma la gramática impone la configuración informativa, por un lado; y de qué forma la situación informativa afecta a la conformación gramatical, por otro. Este planteamiento aúna el debate teórico que suscita la tríada estructura informativa / (inter) subjetividad / miratividad, al tiempo que exige el análisis de la estructura gramatical del español en diversos niveles (fonético-fonológico, léxico-semántico, sintáctico y discursivo).

La relación entre la configuración informativa y la estructuración lingüística no es un fenómeno nuevo. Solo por citar algunos ejemplos del español, la manera en la que la disposición informativa puede afectar a la forma lingüística se observa en una gran variedad de fenómenos, como la alternancia del artículo definido e indefinido (Leonetti 1999), la posibilidad y el funcionamiento de la elipsis (Brucart 1999), la configuración y el comportamiento de las construcciones hendidas (Gutiérrez Ordóñez 1997: 2015), el orden de palabras y las funciones informativas como el tema, el rema, el tópico o el foco (Padilla 2005), la distribución de algunas partículas discursivas (Schwenter 1999, 2001, 2003), o la configuración y alternancia de estructuras contrastivas, como adversativas y concesivas (Cuenca 1991; 
Rodríguez Rosique 2008; Pérez Saldanya y Salvador 2014). La intuición que lleva a plantear este proyecto es que, si se tienen en cuenta algunos de los aspectos que se han discutido en las secciones precedentes, se abren ante nosotros un sinfín de posibilidades que demuestran la interacción entre configuración informativa y estructuración lingüística: por un lado, algunos de los fenómenos que han formado parte del inventario de temas lingüísticos tradicionalmente vinculados con la situación informativa pueden abordarse desde otra óptica; por otro, la nómina de fenómenos lingüísticos que se ven afectados por la configuración informativa puede incrementarse considerablemente.

\subsection{Distribución de los demostrativos: conocimiento compartido y grados de activación}

Más allá de los usos canónicos, el análisis del corpus GestINF permite abordar algunos empleos periféricos de los demostrativos, que adquieren otra luz al combinar el conocimiento compartido y el grado de activación.

La clase de los demostrativos incluye un conjunto de pronombres, determinantes o adverbios que expresan la situación de una entidad con respecto a los participantes en la interacción (RAE/AALE 2009: 2034), como se observa en Me gusta esto, Esa chica tiene problemas o Aqui se está bastante bien; en este sentido, se conciben como una categoría deíctica, en la medida en que remiten a las coordenadas espaciotemporales del acto de enunciación (Lyons 1977: 636). La deixis convoca tres grandes paradigmas lingüísticos -la persona, el espacio y el tiempo-, pues los tres arrancan de un centro común: el yo - aquí - ahora.

Los elementos demostrativos fusionan dos sistemas deícticos (la persona y el espacio), en la medida en que indican especificaciones de la tercera persona que se organizan según grados de distancia con respecto al origo, o centro de orientación deíctica (Eguren 1999: 940): así, este indica cercanía; ese expresa punto intermedio entre cercanía y distancia; y aquel transmite distancia. Esto sucede, sobre todo, cuando los demostrativos funcionan en términos prototípicos; es decir, cuando expresan deixis ad oculos ${ }^{9}$, o están relacionados con la mostración. Los demostrativos, sin embargo, son elementos deícticos opacos (Eguren 1999: 940-941), pues requieren información gestual o contextual adicional para identificar con precisión al referente, pueden remitir a distintos componentes de la situación comunicativa, su referencia puede alterarse por medio de gestos, y tienen usos fóricos -es

\footnotetext{
${ }^{9}$ Para una clasificación y descripción temprana de los tipos de deixis en español, véase Cifuentes (1989).
} 
decir, pueden remitir a un referente del contexto lingüístico o cotexto-. Los usos fóricos no dejan de ser deícticos, pero se diferencian de los ostensivos -vinculados con la mostración- en que convierten el texto en el espacio de señalamiento (RAE/AALE 2009: 2034-2045).

La flexibilidad que caracteriza al sistema permite muchas veces al hablante reinterpretar las dimensiones espaciales «objetivas» asociadas a los demostrativos, y proyectar la distancia o cercanía que estos convocan sobre otros niveles de significado. Este fenómeno se observa especialmente en los casos de posposición (La chica esta), donde el demostrativo ocupa una posición posnominal en sintagmas encabezados por artículos determinados o por posesivos, o integrados por nombres propios. Frente a la opción antepuesta no marcada, en la que el demostrativo aporta al sintagma definitud y localización -por ejemplo, en Esta chica el determinante indica que el referente puede ser identificado y que, al mismo tiempo, ocupa una posición cercana al origen-, en los casos de posposición esta labor se bifurca (Eguren 1999; RAE/AALE 2009): el artículo, el posesivo o el nombre propio se encargan de la definitud del referente, y el demostrativo indica su localización. Este reparto de papeles favorece que la función localizadora del demostrativo se intensifique (Eguren 1999: 951), y genera una construcción altamente expresiva que habitualmente convoca valores de ironía, distancia o menosprecio (RAE/AALE 2009: 2084).

El carácter negativo asociado a la posposición se observa en los ejemplos (1) y (2), extraídos de la conversación 5 del corpus GestINF, que se desarrolla entre el personal de bibliotecas de la Universidad de Alicante.

(1) H3: esta decía $\rightarrow$ / que había que conservar solamente [treinta libros] [(risas)]

H1: [TREINTA / sí] // [la Marie Kondo]

H4: [exacto]

H2: [Marie Kondo es que se $\rightarrow$ ]

H1: [Marie Kondo esa] // si te]

(2) H4: y anda-/ ANDA que son baratos / ¿eh? $\uparrow$

H3: bu / carísimos

H4: $(($ anda que son $\rightarrow))$

H3: unos tochos así / en papel de ese de BIBLIA

H1: hm

H3: unos tochos [ASÍ]

H4: [eso-/ eso los MEMENTOS]

H3: [a mí me da un-] // sí / los mementos estos // me dan una PENA $\rightarrow$ $/ /{ }^{\circ}$ (me da pena el profesor que se los tiene que tragar $)^{\circ} /$ ((porque)) eso es infumable / pien-/ pienso yo / pero bueno // a ellos [les gusta.]

H4: [nooo / esos son más de consulta] / esos no son de $\rightarrow$ 


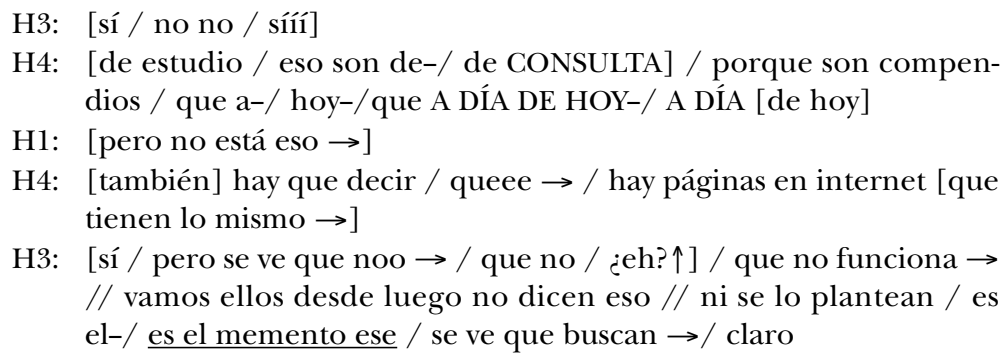

Como se comentó más arriba, a los participantes se les facilitó un texto sobre la filosofía del orden de la youtuber Marie Kondo, quien recomienda no acumular cosas en casa. A lo largo de la conversación, los interlocutores muestran su desacuerdo con la propuesta, y esto se materializa en la posposición del demostrativo que lleva a cabo H1 en la última intervención del ejemplo (1). En el caso de (2), se está discutiendo sobre las nuevas adquisiciones que se catalogan en la biblioteca, y, en la octava intervención, H3, mediante la posposición del demostrativo, expresa su distancia ante un tipo de obra de consulta -los mementos- por la ardua lectura que imagina que suponen estos libros.

No obstante, no es necesario que exista una carga negativa para que se produzca la posposición del demostrativo. En otras ocasiones, el fenómeno está vinculado con la distribución del sistema en relación con los grados de activación. Esto es lo que parece suceder en la última intervención de H3 en el ejemplo (2), donde el carácter peyorativo parece haberse relajado; y lo que se observa también en la posposición que realiza H3 en su última intervención del ejemplo (3):

(3) H4: [¿̇de qué asignatura estáis hablando?]

H2: [no sé por qué]

H1: claro / me he quedado ra-/ [digo Lingüística no damos]

H3: [historia de la lengua]

H4: [ahh // bueno]

H2: [tiene cara] de Lingüística / porque [antes he dicho el profesor de Lingüistica]

H3: [sííi]

H2: y ya $\rightarrow$

H3: [pero es que siempre le llamo así / ¿eh? $\uparrow]$

H4: [tiene cara de lingüística]

H2: [yo también]

H1: [(risas)]

H3: [el hombre de Lingüística (entre risas)]

H2: [y nos entendemos (entre risas)]

H3: y no tiene nada [que ver con la Lingüística / el hombre ese] 
El ejemplo (3) está extraído de la cuarta conversación, en la que participan estudiantes del Grado en Español de la Universidad de Alicante. Las chicas están hablando sobre uno de sus profesores (el de Historia de la Lengua), al que una de ellas le atribuye erróneamente la condición de profesor de Lingüística. Mediante la posposición, la hablante no parece estar expresando distancia hacia el referente, sino que el uso del demostrativo posnominal más bien parece cumplir una función distribucional vinculada con los grados de activación. Un demostrativo antepuesto al sustantivo (la posición no marcada) necesita únicamente que el sintagma esté activado en la mente del interlocutor; un pronombre demostrativo exige que el referente constituya el foco de activación ${ }^{10}$; y, finalmente, un demostrativo pospuesto indica que el referente puede comenzar a desactivarse -esto es, que ha sido foco de activación ${ }^{11}$ y puede empezar a perder prominencia en el devenir discursivo-.

La RAE/AALE (2009: 2084) repara también en que el demostrativo pospuesto puede utilizarse para identificar personas o cosas que no han sido activadas situacional o cotextualmente, pero que forman parte del conocimiento compartido, como sucede en (4) y (5), ambos extraídos de la conversación 4. En el pasaje al que remite el ejemplo (4), los participantes están hablando sobre los mercadillos callejeros improvisados por los vecinos para desprenderse de los enseres que ya no les son útiles. Por su parte, en el ejemplo (5) -que relata el afán coleccionista de uno de los participantes en la conversación (H4) - se alude a la revista satírica El Jueves; y, en concreto, a uno de sus números.

(4) H1: [era EN UNA CALLE $\rightarrow$ / eran LOS VECINOS $\rightarrow$ // sí] / allí eran los vecinos de esa $\rightarrow$ calle / por ejemplo

H2: [ya ya ya]

H3: sí

H1: pues que quedaban un día / sacaban todos / y en la puerta de SU CASA // pues sacaban / pues eso / sus trastos / lo que $\rightarrow$ no $\rightarrow$ QUERÍAN ya $\rightarrow$ [o que tal]

H3: [sí.]

H1: supongo que antes de tirarlo $\rightarrow /$ pues si a alguien le aprovechaba $\rightarrow$ // y-/ y tenían de todo / o sea / pues ese-/ el juego de café $\underline{\text { ESE }} \rightarrow$ que te regalaron

H3: sí

${ }^{10}$ No en vano, Eguren (1999: 943-944) indica que debe seguir obligatoriamente a su antecedente: Cuando Pedro se encuentra con Juan , este $_{i}$ siempre le saluda.

${ }^{11}$ La vinculación del demostrativo pospuesto con el foco de activación puede explicar que muchas veces se haya relacionado con el rema (Eguren 1999: 951). En estos casos, se puede generar un valor contrastivo: el sintagma con demostrativo pospuesto señala un referente en oposición a otro (esta implicación parece estar actuando en la última intervención de H3 en el ejemplo 2). 
H1: que no habías gastao nunca / que era súper horrible / pues lo pones / si sacas $\rightarrow$ tres euros / pues $\rightarrow$

(5) H4: con cómics / que yo soy $\rightarrow$ / ahora-/ ahora ya llevo / pues no / ahora no-/ bueno / me sigo comprando El Jueves todas las semanas / eso sí // [ta-/ también tengo]

H1: [(risas) $]$

H2: [aahh $\rightarrow$ / qué bueno]

H3: [ElJueves]

H4: cientos y cientos y cientos de Jueves / porque creo $\rightarrow$ / fijate cuando salió la-/ la de dos mil siete $\rightarrow$ / la famosaa $\rightarrow /$ portada esa dee $\rightarrow$

H3: de los reyes

H1: [de los reyes]

H4: [de los reyes / de los reyes] / eeeee-/ bueno / eran príncipes entonces

En estos casos, el demostrativo cumple una función evocadora (RAE/ AALE 2009: 2255 $)^{12}$, en el sentido de que puede emplearse para aludir a referentes que se localizan en las asunciones compartidas por el hablante y sus interlocutores. La localización, concebida como distancia, sigue funcionando, pero se interpreta metafóricamente: el demostrativo remite a un espacio contextual implícito en el que se sitúan las entidades, como si estuvieran físicamente presentes. En términos de activación, estas entidades (el juego de café y la portada de la revista) serían accesibles; esto es, no han sido activadas como tales, pero están relacionadas con información activada mediante relaciones de discurso: en los mercadillos vecinales es habitual encontrar juegos de café, y las portadas de la revista cómica -o de carácter satírico-humorístico- El Jueves suelen ser famosas por la controversia que despiertan. No obstante, la identificación de los referentes remite al conocimiento compartido de los interlocutores, generado por la superposición de comunidades culturales: la gente de determinada generación tiene en casa un juego de café que le han regalado y que no usa porque no le gusta; y la gente de determinada generación, aficionada a las revistas satíricas, recordará la polémica portada de El Jueves en la que el entonces príncipe Felipe y su prometida Letizia aparecían en una escena sexual en la que comentaban, como única preocupación laboral, el tema de su descendencia.

${ }^{12}$ No es necesaria la posposición, pero el uso evocador de los demostrativos suele ir ligado a cierto carácter marcado. En ocasiones, porque estos usos se activan cuando el sintagma va acompañado por adjetivos valorativos (RAE 2009: 2034-2045); en otros casos, porque existen otras marcas que alertan al destinatario de la función especial que está desarrollando el demostrativo. Así se observa en la falta de concordancia que se produce entre demostrativo y núcleo nominal en el siguiente ejemplo, extraído también de la conversación 4 del corpus: cómo camb-/ cómo ha cambiao todo /¿̨eh? $\uparrow /$ esos-/ esos libros / ese-/ ESE la ley $\rightarrow$. Este procedimiento resulta bastante rentable en el ámbito coloquial. 
En definitiva, el comportamiento periférico de los demostrativos puede explicarse mediante la intersección de dos parámetros ortogonales vinculados con la configuración informativa: el conocimiento compartido y la activación.

\subsection{La focalización o la función discursiva del énfasis}

El papel de la activación va a resultar crucial también a la hora de identificar una de las funciones discursivas que puede desempeñar el foco informativo. El foco es una función pragmática que remite a la contribución del fragmento en relación con el discurso previo y a su configuración gramatical (RAE/AALE 2009: 135). Aunque se han propuesto varias definiciones (cf. König 1991; Gutiérrez Ordóñez 1997; Zubizarreta 1999; Padilla 2005), se suele concebir como una forma de marcar énfasis sobre una determinada información:

De forma semejante a lo que ocurre en óptica, el foco es un punto en el que confluyen los vectores intencionales del emisor. Su propósito comunicativo suele ser el de llamar la atención del receptor con el fin de vencer en este una predisposición contraria o simplemente de subrayar su importancia en el proceso informativo en el que se hallan inmersos (Gutiérrez Ordóñez 1997: 34).

El foco puede estar destacado por el acento tonal (A: Ayer vino Juan. B: No, PEDRO vino ayer); por la inclusión de determinadas partículas (Incluso Pedro vino ayer); o por la estructura misma (El que vino ayer fue Pedro), con mayor o menor grado de construccionalización.

En general, se asume la existencia de dos tipos de focos (RAE/AALE 2009: 4658-4660): el presentativo o informativo, que coincide con toda la información que se suministra; y el contrastivo, que identifica un elemento entre un conjunto. Un ejemplo de foco presentativo lo constituyen las estructuras existenciales, como se observa en (6), extraído de la conversación 5:

(6) H4: [hay-/ hay u-/ hay una familia]

H3: [yo cuando vi gente rebuscando] en la basura / [digo madre mía $\rightarrow$ ]

H1: [sííi]

H4: [hay una familia]

H2: se ha acentuado

H3: [no lo había visto / ¿eh? $\uparrow]$

H2: [se ha acentuado / sí]

H1: [en los contenedores de ropa]

H3: [yo hasta el dos mil siete o por ahí / no lo había visto]

H2: [sí / se ha acentuado mucho] 
H3: y me $\rightarrow$ // joer que bajón

H4: hay una familia que está $\rightarrow$ metida directamente en-/ en-frente deel-/ del punto este de recogida que hay en Castalla $\rightarrow$

H3: ah / sí / también

H4: eeee-/ a la hora que vayas hay alguien // hay alguien

En este fragmento, a partir de la necesidad de desprenderse de las cosas que ya no se usan, los participantes han empezado a hablar de las consecuencias sociales que tuvo la crisis económica de 2008. Con este contexto de fondo, la información «hay una familia que está enfrente del punto de recogida de enseres y que están allí a todas horas», constituye un foco informativo, que $\mathrm{H} 4$ presenta en diferentes turnos.

Las alternativas con las que el foco contrastivo establece relación pueden estar directamente explicitadas en el discurso, como se observa en (7); o implicadas de manera más sutil, como sucede en (8). Ambos ejemplos están obtenidos de la conversación 1.

(7) H2: [yo que sé] / por ejemplo / el tema de los toros // la mayoría de la gente de mi generación / y yo imagino que en la vuestra aún serán menos gente a la-/ la que le guste ir a los toros $\uparrow /$ por decir algo / pero también / hay mucha gente que-/ que aun siendo de mi edad o de la vuestra / le GUSTAN

(8) H3: hombre / para dominar el humor / hay que ser $\rightarrow$

H4: claro

H1: [sí / la verdad es que sí]

H3: [hay que tener] $\rightarrow /$ unos cuantos $\rightarrow /$ tornillos.

H4: ((hombre) ) / aunque / hoy en día / los límites del humor ya $\rightarrow$ / [poco a poco parece que se va restringiendo]

H3: [pues-/ pues-/]

H4: [lo mismo en relación con la $\rightarrow$ ]

H3: [a mí me EN-CAN-TA] el humor que tenemos ahora $\uparrow$ / creo que ha cambiado muchísimo

Precisamente porque las alternativas pueden estar implicadas, algunos autores consideran que la noción de contraste puede resultar demasiado fuerte, y prefieren hablar de foco exhaustivo; es decir, aquel mediante el que no se expresa tanto la exclusión de determinadas opciones como la elección de una en particular (RAE/AALE 2009: 4658-4660). No obstante, es cierto que en muchas ocasiones el carácter contrastivo es el más prominente, como ocurre cuando la información va precedida del adverbio afirmativo sí, según refleja (9), extraído de la conversación 5:

(9) H2: de todas formas yo algunos libros sí que los tendría en electrónico / antes que conservarlos en papel // OTROS no / hay títulos $\rightarrow$ 
En el ejemplo (9), la hablante destaca que algunos libros de la biblioteca deberían estar en formato electrónico, frente a otros que deberían seguir en papel. El contraste entre el foco y las alternativas se marca aquí doblemente: por un lado, la información focal va precedida, como se ha comentado, del adverbio afirmativo sí, y contrasta con las alternativas -los diferentes libros que se pueden encontrar en una biblioteca- a las que, en cierto modo, se ha aludido durante esta fase de la conversación; por otro, mediante la acentuación de OTROS y la estructura distributiva, las alternativas se convierten ahora en foco en una especie de mecanismo recurrente.

Parece una cuestión asumida la asociación de los focos a la información nueva o remática (RAE/AALE 2009: 4658-4660, 2011: 482-488). Sin embargo, si se tiene en cuenta el parámetro de la activación, se pueden identificar nuevas funciones discursivas vinculadas con el carácter enfático del foco. Esto es lo que sucede en el ejemplo (10), extraído de la conversación 1:

(10) H2: cuando me compré yo el coche // me dijeron / vamos a plantar un árbol / quee todos los-/ por cada Volkswagen que compras / plantan un árbol / y lo plantan allí en-/ en Albacete / en la provincia

H4: ¿̇í̂? $\uparrow$

H3: [¿¿ííí? $\uparrow$ (risas) ]

H2: [eenn-/ en la sierra de Albacete $\rightarrow$ ]

H1: [(risas) ]

H3: [mira / este es el Volkswagen (entre risas)]

H2: eeee-/

H3: [¿quéé taal? $\rightarrow$ ]

H2: [me refiero a nivel nacional]

H4: [claro / claro]

H2: los que compran en China / no sé lo que harán (entre risas)

H3: (risas)

H2: no sé si plantarán muchos árboles (entre risas) // pero $\rightarrow$

H3: plantarán bambú

H2: [pero sí está $\rightarrow$ ]

H3: [dan más oxígeno]

H2: y luego salió al poco tiempo / digo ;ah! / mira / mira qué empresa / ¿no? $\uparrow$ / está comprometida con el medio ambiente y tal

H4: y después salió lo de Volkswagen

H2: y luego salió el $\rightarrow$

H4: el-/

H2: la historia esta de los diésel / quee $\rightarrow$

H4: quee mentían con lo que $\rightarrow$ /

H2: sí

H4: las emisiones a la atmósfera

H2: y digo macho / no se SAL-VA NA-DIE / no se salva nadie (pausa prolongada: 2 segundos) 
Cabría pensar que la información focalizada en la última intervención de H2 podría deberse a una negación interna, o de constituyente; es decir, aquella en la que no se rechaza todo el contenido proposicional, sino solo algún segmento. Este tipo de negación es la que habitualmente se pone en relación con el foco informativo (RAE/AALE 2009: 5633-5634). No obstante, la configuración informativa que refleja (10) se parece más a la que legitima la negación externa; esto es, aquella en la que se refuta un contenido proposicional relacionado con el discurso previo. En efecto, H2 está contando cómo el comportamiento de Volkswagen -plantar un árbol cada vez que algún comprador adquiriera un vehículo- parecía implicar cierto compromiso ecológico por parte de la marca; sin embargo, el descubrimiento de la manipulación de las emisiones de $\mathrm{CO}_{2}$ en los vehículos bloquea la adhesión empática con la compañía. La información No se salva nadie, en realidad, no es remática con respecto al discurso precedente; podría más bien considerarse inferible, en términos de activación: la proposición no ha aparecido como tal, pero se deriva como evaluación que resume el relato anterior de H2. En este sentido, el foco cumpliría un papel discursivo reasuntivo o sintetizador.

Algo semejante sucede en (11), también extraída de la conversación 1:

(11) H2: ¿ंvale? $\uparrow /$ me eliminé la cuenta // a los cinco años o cuatro años / un día tenía que entrar para buscar a una persona que nooo co-/ conseguía contactar / o sea / se me reactivó y estaba todo perfecto /o sea / Tú le das a eliminar [la cuenta $\rightarrow$ ]

H4: [sí]

H2: [y no se elimina]

H4: [nunca-/ nunca puedes / eliminar-/ eliminar la cuenta.]

H2: [después de CUATRO o CINCO años $\rightarrow$ ]

Como ocurría en (10), no puede decirse que la información que representa la acentuación de CUATRO o CINCO constituya información nueva o remática; más bien estamos ante el foco de activación, en términos discursivos: que han pasado cuatro o cinco años desde que el hablante eliminó su cuenta y que, a pesar de haber transcurrido todo este tiempo, la cuenta no se ha eliminado, constituye información máximamente prominente en la mente de los participantes. De nuevo, al igual que en el caso anterior, el foco parece cumplir una función reasuntiva o sintetizadora.

Ejemplos como (10) y (11) demuestran que si, en vez de tener en cuenta únicamente la oposición información conocida vs. información nueva, se atiende al continuo de la activación cognitiva, el foco informativo puede vincularse con información que constituye el foco de activación en el discurso previo. En estos casos, el énfasis normalmente asociado a esta función pragmática suele desempeñar un papel reasuntivo o sintetizador, que 
permite imponer la perspectiva del hablante ante el tema abordado antes de que se cierre definitivamente y se pase a otro asunto.

\subsection{Las interrogativas en el discurso: miratividad y gestión conversacional}

La colaboración entre la dicotomía información nueva / información conocida y el continuo de activación permite también arrojar luz sobre el funcionamiento discursivo de la interrogación, al tiempo que explica la vinculación de las estructuras interrogativas con la intersubjetividad y con la miratividad.

La función prototípica de la interrogación es hacer una pregunta (Escandell Vidal 1999: 3931-3934; RAE/AALE 2009: 4906); esto es, mediante una estructura interrogativa, el hablante solicita al destinatario información que no conoce. En este sentido, las interrogaciones constituyen proposiciones abiertas, pues siempre incluyen una incógnita o variable. Así funcionan las interrogativas que aparecen en (12), extraídas de la conversación 5:

(12) H4: [y me gusta-/ y me gustan] los libros antiguos

H2: $[j a h ! / ~ ¿ t i e n e s ? \uparrow]$

H4: [que ahora también me voy] comprando $\rightarrow$

H2: [¿de qué época? $\uparrow]$

Mientras que en la interrogativa total que aparece en la primera intervención de H2 la incógnita afecta a la polaridad de oración -la hablante desconoce si H4 tiene libros antiguos-, en la interrogativa parcial de su segunda intervención la variable solo recae sobre un segmento de la proposición -la época a la que pertenecen-.

Como se comentó en la segunda sección, la interrogación permite diferenciar entre la información conocida -aquella que se da por asumida-y la información nueva, y delimitar el foco informativo. No obstante, no todas las estructuras interrogativas se utilizan para solicitar información o hacer preguntas (Escandell Vidal 1999: 3931). En muchas ocasiones, el hablante puede utilizar una interrogación para reforzar la afirmación que acaba de realizar. Es lo que sucede con los apéndices confirmativos (RAE/AALE 2009: 4923-4927), como el ives? que aparece en (13), extraído de la conversación 5 ; o el $\dot{\zeta} e h$ ? que se observa en (14), sacado de la conversación 4:

(13) H3: [sí sí sí sí / pero / bueno / se queda ahí quietecito]

H4: [sí / como que si acumula]

H2: [porque nosotros] hemos recibido donaciones [en la biblioteca] $\rightarrow$

H1: [que-/ bueno / sí $\rightarrow$ ]

H2: que mejor no decir [los nombres] $\rightarrow$ 


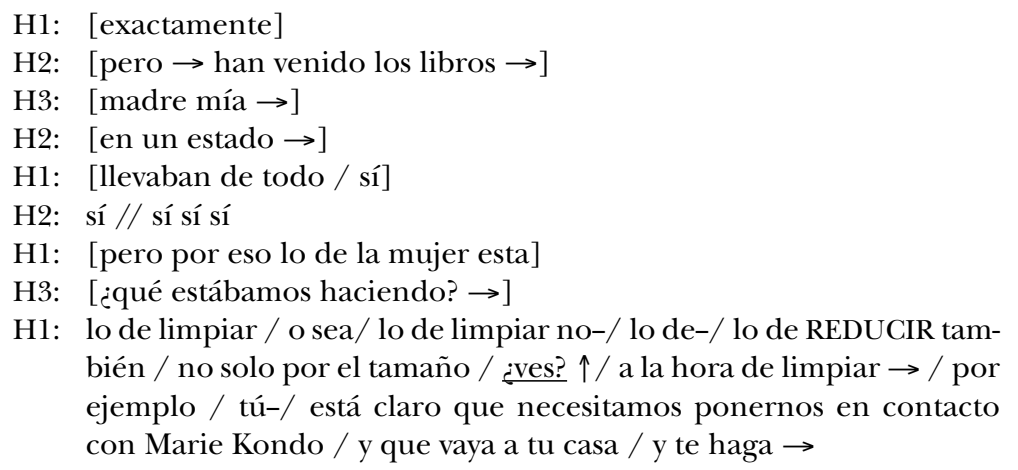

(14) H2: [métete en vox] y ves los seguidores-/ TUS seguidores que lo siguen // te vas a sorprender / ¿eh? $\uparrow$

H4: [eeee-/ eeee-/]

H3: [sííi

H2: [porque yo dije / dejar de seguir a tal] [(risas)]

H1: [pero serán seguidores] que no apoyen / sino que están ahí por-/ para [saber qué suben]

H2: [ique no que no que no!]

H3: no no / seguidores que $\rightarrow$ luego te pones a pensar y dices vale / sí / [seguro que vota a vox (risas)]

H2: [ me cuadra TODO // sí sí sí]

H4: [una de-/]

H2: [banderita por aquí / tal]

H1: [i¿en serio?! $\uparrow]$

Mediante estos recursos el hablante solicita la participación de sus interlocutores, bien porque presenta la información anterior como natural, lógica o evidente -tal como sucede en (13)-; o bien porque se espera la aquiescencia o complicidad de los destinatarios -según se ve en (14)-. En este sentido, estos mecanismos constituyen verdaderos casos de intersubjetividad en términos de Nuyts (2012), pues el hablante recurre a estrategias discursivas para que la información cuente como compartida por todos los participantes que intervienen en la conversación; asimismo, se trata de casos de intersubjetividad en términos de Traugott (2010), pues estas estructuras reflejan cierta evolución hacia significados que prestan cada vez más atención al destinatario y a la situación comunicativa.

La interrogación no solo está vinculada con la intersubjetividad, sino también con su hermanastra discursiva: la miratividad. En efecto, se ha señalado la existencia de determinadas marcas mirativas que aparecen bajo

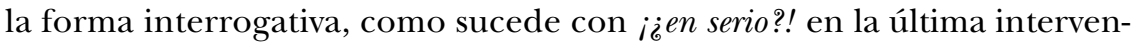
ción de (14), o como se observa en el valor de isi? en (15), extraída de la conversación 1: 
(15) H1: [a mí eh que todo eso me dan mucho asco] / o sea/ el pepperoni $\rightarrow$ / los embutidos $\rightarrow$ / me dan mucho asco

H3: [jahí / muy bien! // eso es pura basura]

H2: [¿̇sí? $\uparrow /$ ibuah! / pues yo $\rightarrow$ / puf (soplido) ]

En estos casos, $\underset{i}{ }$ en serio?! y $\dot{i}$ sí? permiten al hablante expresar que la información que acaba de recibir -y que constituye el foco de activaciónno forma parte de su horizonte de expectativas, sino que representa información no integrada en su estructura de conocimiento (DeLancey 2001), lo que desemboca en una reacción de sorpresa o de mente no preparada (Aksu-Koç y Slobin 1986).

Esta reacción evaluativa de sorpresa, o de mente no preparada, se observa también cuando determinadas partículas preceden a la estructura interrogativa, como sucede con į Cómo (que)... ?! ${ }^{13}$ (Escandell Vidal 1999: 3965-3969; RAE/AALE 2009: 4947), según se ve en (16), obtenido de la conversación 4:

(16) H4: [de todas formas] / a mí la pregunta no me parece $\rightarrow$ en plan RARA $/$ [o sea]

H2: [i¿cómo que no?!]

No obstante, para que la interrogación desencadene un efecto mirativo, no es necesario que aparezca una partícula, aunque eso facilita las cosas, sino que basta con que la información que contiene la interrogativa constituya el foco de activación (Rodríguez Rosique 2018), tal como se observa en (17) y (18), ambas extraídas de la conversación 4:

(17) H1: como ahora solo quedan los trabajillos esos en plan finales

H3: [claro]

H1: [que también son $\rightarrow$ ]

H2: [bueno / trabaji-/]

H3: [a ver / trabajillos (risas)]

H2: [¿ihas dicho TRABAJILLOS!?]

H3: [trabajillos tampoco (entre risas)]

(18) H1: [¿̉pero cuánto] dura el episodio? // [¿¿una hora?]

H2: [es que han dicho que la-/] laaa última temporada-/ los últim-/ los finales van a durar como $\rightarrow$ / una hora / ( (o sea)) UNA PELÍCULA / ¿sabes? $\uparrow$

H1: yaaa

\footnotetext{
${ }^{13}$ De acuerdo con Escandell Vidal (1999), a diferencia de la interpretación neutra de ¿Que...? -que puede desencadenar asombro o sorpresa, pero no necesariamente-, ¿̨ómo $q u e .$. ? siempre está asociada a una interpretación negativa. En este sentido, para la autora, lo que compartirían ambas marcas sería el carácter citativo: estas interrogaciones remiten a información que ha suministrado otro hablante.
} 


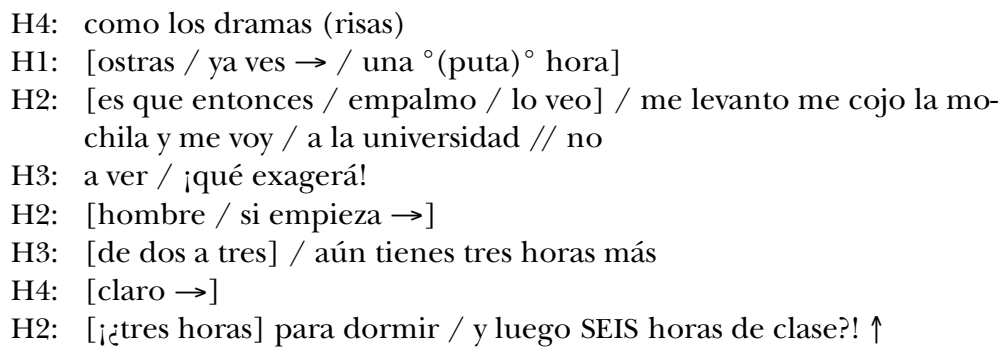

Lo que sí caracteriza a las interrogativas que desencadenan un efecto mirativo es que siempre exhiben una entonación marcada, que las sitúa a medio camino entre la interrogación y la exclamación; es decir, constituyen interrogativas exclamativas (Alonso 1999; Escandell Vidal 1999), lo que explica que suelan aparecer simultáneamente con signos de interrogación y exclamación (RAE/AALE 2009: 4906).

Más allá de la labor de la interrogación en la organización de la estructura informativa, y de su condición de puente entre la intersubjetividad y la miratividad, la función de una estructura interrogativa puede ir más allá y adentrarse en la gestión conversacional, como sucede en (19), extraída de la conversación 1, y en (20), obtenida de la conversación 5:

(19) H2: ¿yyy / la gente de vu-/ dee vuestra generación $\uparrow /$ utiliza más Instagram que Facebook? $\rightarrow$

H3: sí

H1: sí

H3: sí sí sí

(20) H4: ¿y seguimos hablando del tema que estábamos hablando? $\uparrow$ (entre risas)

H2: yo creo que no / porque es un tema [demasiao polémico]

H3: $\left[\right.$ sí $\left./ /{ }^{\circ}(\text { vamos a hablar de otro })^{\circ}\right]$

Los participantes que formulan estas preguntas van a adoptar un papel activo en el progreso de la conversación, y se erigen, así, en una especie de moderadores, que organizan el avance temático de cada una de las interacciones. La interrogación amplía sus límites y adquiere de esta forma un alcance metaconversacional.

\subsection{Configuración informativa y construccionalización: es que es eso}

Si en el apartado anterior se ha comprobado cómo una estructura lingüística abandona la esfera de la gramática para desempeñar una función en la interacción, en este caso nos detendremos en la manera en la que 
una estructura que emerge de la interacción se convierte en construcción (Traugott y Trousdale 2013) -es decir, empieza a formar parte de la gramática (Kaltenböck, Heine y Kuteva 2011)-. Esto es lo que sucede en el caso de es que es eso, según se observa en (21) y (22), obtenidos ambos de la conversación 4. Los dos ejemplos, además, pertenecen al pasaje en el que las participantes están comentando uno de los textos desencadenantes de la conversación; en concreto, aquel en el que la RAE responde a través de Twitter a una consulta de una usuaria sobre el género de los adjetivos. Este texto generó cierta polémica: por un lado, la pregunta podía verse como una provocación (se acababa cuestionando por qué no se puede decir marrona, y si eso constituye un caso de discriminación); por otro, la respuesta de la institución, al utilizar imbécil como ejemplo de adjetivo común -sin variación de género-, podía interpretarse como una actitud descortés.

(21) H2: yo e-/ la duda-/ la duda que tiene la chica es normal / no la veo como para llamarla imbécil

H4: o sea / es que pa [eso está la rae]

H2: [la-/ la única-/ lo único que dice]

H3: [es de sentido común]

H2: ya $\rightarrow$ / [pero me refiero]

H1: [claro]

H2: la-/ a lo mejor la FORMA en la que-/ en la que LO PREGUNTÓ de ¿estás ofendiendo a las marronas? $\downarrow /$ pero si llega a preguntar POR QUÉ [hay-/ hay colores que son]

H4: [ah / sí]

H1: [es que es ESO]

(22) H4: [que lo-/] que lo leí en plan $\rightarrow /$ porque al principio te pone solo como la definición // y lo leí y fue como tal // pues $\rightarrow$ es como-/ es porque es un adjetivo dee-/ dee-/ de una terminación / y leí tal tal y tal / y co-/ como no-/ no veo el-/ el problema [en esta definición.]

H2: [pero a ver] / sí que tiene razón Violeta que hay muuuchos adjetivos [para decir]

H1: [ya / es que es eso]

En la construcción es que es eso aparecen tanto la controvertida coocurrencia de es que como el pronombre neutro eso; sin embargo, estos elementos ya no parecen funcionar de manera composicional. La coocurrencia de es que ha sido interpretada de diversas maneras. Para algunos autores estamos ante la combinación del verbo ser con una subordinada sustantiva encabezada por la conjunción que (Fernández Leborans 1999; RAE/AALE 2009: 4371, 5402). De acuerdo con Fernández Leborans (1999: 2403-2407), la estructura constituye una oración copulativa con valor identificativo, donde el segmento poscopular especifica un evento que, a través de una relación 
discursiva, puede entenderse como el motivo de un estado de cosas previamente aludido: Estoy preocupada por mi hijo: no quiere comer, no estudia y se comporta raro $>$ (Eso) Es que está enamorado; El suelo está mojado > (Eso) Es que ha llovido (Fernández Leborans 1999: 2405). En estos casos, el segmento precopular suele aparecer elidido, aunque puede estar representado por el pronombre neutro eso, que no alude al estado de cosas que se intenta explicar, sino a la razón o motivo que provoca el mismo. En otras ocasiones, el funcionamiento de es que se asemeja bastante a una construcción de relieve focal (Fernández Leborans 1999; RAE/AALE 2009: 4684; Fuentes 2015) ${ }^{14}$. La estructura admite ahora como miembro precopular una perífrasis de relativo que funciona como información presupuesta, lo que hace que el miembro poscopular destaque como foco: A: Usted dirá. ¿Qué le ocurre? B: Pues verá... (Lo que me ocurre / Lo que me pasa) Es que tengo fuertes dolores de cabeza; A: ¿̈Funciona? B: Sí, sí. A: Pues [lo que pasa ${ }^{15} /$ lo que ocurre] es que el de dentro no funciona (Fernández Leborans 1999: 2406). El segmento introducido por es que se interpreta aquí como la justificación de lo que se ha dicho o de lo que ha sucedido anteriormente -de manera semejante a como haría una causal de enunciación (RAE/AALE 2009: 5402-5403)-, que puede acabar derivando en una excusa o incluso en una reprobación. Para muchos autores (Porroche 1998; Pérez Saldanya 2008; Fuentes 2009), el comportamiento de este es que ya no obedece a una estructura composicional, sino que estamos ante un marcador discursivo.

En el caso de (21) y (22) no se puede hablar de una estructura identificativa, ni de una estructura focal, ni siquiera de un caso de es que como marcador. Más bien parece que es que es eso funciona como una construcción (Traugott y Trousdale 2013: 22), con una forma nueva -se trata de una estructura fija, que no permite variaciones (*es que es esto; *es que son esas cosas; *lo que pasa es eso) - y con un nuevo significado. En concreto, a través de esta nueva construcción el hablante identifica un argumento, que acaba de emitir su interlocutor y que constituye el foco de activación -a lo que contribuye la presencia de eso-, y lo destaca como suficiente (Portolés 1998) frente a cualquier objeción posterior. Esta nueva construcción se comporta, por tanto, como un reforzador de la aserción (Martín Zorraquino y Portolés 1999: 4147-4148), que se interpreta como una estrategia de cooperación entre hablante e interlocutor en la construcción del significado. La construcción emerge, así, como intersubjetiva, tanto desde la perspectiva de Traugott (2010) -pues el significado evoluciona hacia la inclusión progre-

\footnotetext{
${ }^{14}$ Precisamente el carácter focal de la estructura originaria ha permitido que es que evolucione hacia otro valor: el intensivo, que desempeña como operador (cf. Fuentes 2015).

${ }_{15}$ No obstante, sobre el funcionamiento de lo que pasa es que como marcador, véase Reig Alamillo (2011).
} 
siva del destinatario-, como desde la de Nuyts (2012) -pues el conocimiento compartido se emplea como estrategia que permite crear alianzas discursivas y mecanismos de negociación conversacional-.

Si en los apartados precedentes habíamos partido de la gramática para desembocar en la configuración informativa y en la relevancia que esta tiene para la interacción, es que es eso demuestra la manera en la que la configuración informativa acaba convirtiéndose en gramática ${ }^{16}$.

\section{CONCLUSIONes: LA PERTINENCIA DEL CORPUS GeSTINF}

Este artículo pretende haber demostrado la relevancia del corpus GestINF como material orientado que permite evaluar la relación entre la configuración informativa y la estructuración lingüística, así como analizar la postura discursiva del hablante ante una situación informativa concreta. Una revisión de esta interacción hace posible acercarse, desde otra óptica, a fenómenos habitualmente vinculados con la estructura informativa. En este sentido, por ejemplo, se puede explicar la distribución de los demostrativos $-\mathrm{y}$, específicamente, relacionar el demostrativo pospuesto con los grados de activación-, o indagar en las funciones interactivas del foco informativo -que puede desempeñar un papel reasuntivo o sintetizador para destacar la perspectiva del hablante ante un tema abordado-. Asimismo, es posible abordar otros fenómenos que no se han vinculado tradicionalmente con la configuración informativa, y descubrir el papel interactivo que pueden desarrollar las interrogativas, o que la configuración informativa y la interacción que emerge en su seno puede ser una fuente directa de creación gramatical, como sucede con la construcción es que es eso. En términos más generales, el corpus se presenta como una herramienta con enorme potencial para los investigadores en lingüística, en la medida que ofrece interacciones entre hablantes nativos de español que, al estar registradas en formato audiovisual, proporcionan una información bastante completa sobre los distintos parámetros que intervienen en la comunicación.

${ }^{16}$ Para otro caso en el que la configuración informativa puede generar gramática, véase Cifuentes (2018). 


\section{BIBLIOGRAFÍA}

AikHENVAld, Alexandra (2004): Evidentiality, Oxford: Oxford University Press.

- (2012): «The Essence of Mirativity», Linguistic Typology 16, 435-485.

Aksu-Koc, Aihan y Dan I. Slobin (1986): «A Psychological Account of the Development and Use of Evidentials in Turkish». En Wallace Chafe y Johanna Nichols (eds.), Evidentiality: The Linguistic Coding of Epistemology, Norwood: Ablex Publishing Company, 159-167.

Alonso, Ángel (1999): «Las construcciones exclamativas. La interjección y las expresiones vocativas». En Ignacio Bosque y Violeta Demonte (dirs.), Gramática descriptiva de la lengua española, Madrid: Espasa-Calpe, 3993-4050.

Auer, Peter, Jörg Bergmann, Elizabeth Couper-Kuhlen, Susanne Günthner et al. (2011): «A Transcription System for Conversation Analysis», Gesprächsforschung. Online-Zeitschrift zur verbalen Interaktion 12/2, 1-51.

Azorín, Dolores (2002): ALCORE. Alicante Corpus del Español, Alicante: Universidad de Alicante. Formato CD-ROM.

- (2005): «Corpus oral para el estudio del lenguaje juvenil y del español hablado en Alicante: el corpus ALCORE y COVJA», Oralia 8, 265-288.

- y Juan Luis JIMÉNEz RuIz (1997): Corpus oral de la variedad juvenil universitaria del español hablado en Alicante, Alicante: Instituto de Cultura Juan Gil Albert.

Bañón, Antonio, Luis Cortés y Pedro Carbonero (2005): «Corpus para el estudio de las hablas andaluzas I: los corpus del habla de Sevilla y el corpus del habla de Almería", Oralia 8, 161-188.

Bermúdez, Fernando W. (2005): La evidencialidad. La codificación pragmática del punto de vista, Tesis Doctoral, Estocolmo: Stockholms Universitet.

BRIZ, Antonio (2000): «Las unidades de la conversación». En Antonio Briz y Grupo Val.Es.Co. (eds.), Cómo se comenta un texto coloquial, Barcelona: Ariel, 51-80.

- y Marta Albelda (2009): «Estado actual de los corpus de lengua española hablada y escrita: I+D», El español en el mundo. Anuario del Instituto Cervantes 2009, Madrid: Instituto Cervantes, 165-226.

- y Grupo VAl.Es.Co. (2002): Corpus de conversaciones coloquiales, Madrid: Arco/ Libros.

— y - (2003): «Las unidades de la conversación: el acto». En J. L. Girón Alconchel (ed.), Estudios ofrecidos al profesor José Jesús de Bustos Tovar, Madrid: Ed. Complutense, 953-968.

— y - (2014): «Las unidades del discurso oral. La propuesta Val.Es.Co. de segmentación de la conversación (coloquial)», Estudios de Lingüística del Español 35 (1), 11-71.

BRUCART, José María (1999): «La elipsis». En Ignacio Bosque y Violeta Demonte (dirs.), Gramática descriptiva de la lengua española, Madrid: Espasa-Calpe, 27872865. 
CHAFE, Wallace (1994): Discourse, consciousness and time. The flow and displacement of conscious experience in speaking and writing, Chicago: The University of Chicago Press.

Cifuentes Honrubia, José Luis (1989): Lengua y espacio. Introducción al problema de la deixis en español, Alicante: Universidad de Alicante.

- (2018): Construcciones con clítico femenino lexicalizado, Madrid: Verbum.

Clark, Herbert (1996): Using Language, Cambridge: Cambridge University Press.

CuencA, Maria Josep (1991): Les oracions adversatives, València: Institut Universitari de Filologia Valenciana/Publicacions de l'Abadia de Montserrat.

DeLAnCEY, Scott (1997): «Mirativity: The Grammatical Marking of Unexpected Information», Linguistic Typology 1/1, 33-52.

- (2001): «The Mirative and Evidentiality», Journal of Pragmatics 33, 369-382.

Dryer, Matthew S. (1996): «Forms, Pragmatic Presupposition, and Activated Propositions», Journal of Pragmatics 26, 475-523.

DuQUe, Eladio (2016): Las relaciones de discurso, Madrid: Arco/Libros.

Eguren, Luis (1999): «Pronombres y adverbios demostrativos. Las relaciones deícticas». En Ignacio Bosque y Violeta Demonte (dirs.), Gramática descriptiva de la lengua española, Madrid: Espasa-Calpe, 929-972.

EsCandell Vidal, María Victoria (1999): «Los enunciados interrogativos. Aspectos semánticos y pragmáticos». En Ignacio Bosque y Violeta Demonte (dirs.), Gramática descriptiva de la lengua española, Madrid: Espasa-Calpe, 3929-3991.

EtXebarRia, Maitena y María Rosa ViLA (2005): «Corpus para el estudio de las interferencias lingüísticas: los corpus de Barcelona, Lérida y Bilbao», Oralia 8, 213-242.

Fernández Leborans, María Jesús (1999): «La predicación: Las oraciones copulativas». En Ignacio Bosque y Violeta Demonte (dirs.), Gramática descriptiva de la lengua española, Madrid: Espasa-Calpe, 2357-2460.

Fillmore, Charles (1981): «Pragmatics and the Description of Discourse». En Peter Cole (ed.), Radical Pragmatics, Nueva York: Academic Press, 143-166.

Fuentes, Catalina (2009): Diccionario de conectores y operadores del español, Madrid: Arco/Libros.

— (2015): «Pragmagramática de es que: El operador de intensificación», Estudios Filológicos 55, 53-76.

GuTiÉRREZ ORdóÑEz, Salvador (1997): Temas, remas, focos, tópicos y comentarios, Madrid: Arco/Libros.

- (2015): «La familia de las ecuacionales», Revista Internacional de Lingüística Iberoamericana 26/2, 15-37.

Hengeveld, Kees y Hella Olbertz (2012): «Didn't You Know? Mirativity Does Exist!», Linguistic Typology 16/3, 487-503.

Hidalgo, Antonio (2002): Comentario fónico de textos coloquiales, Madrid: Arco/ Libros.

Kaltenböck, Gunther, Bernd Heine y Tania Kuteva (2011): «On Thetical Grammar», Studies in Language 35/4, 852-897.

KöNIG, Ekkehard (1991): The Meaning of Focus Particles, Londres y Nueva York: Routledge. 
LeOnetTi, Manuel (1999): «El artículo». En Ignacio Bosque y Violeta Demonte (dirs.), Gramática descriptiva de la lengua española, Madrid: Espasa-Calpe, 787890.

Levinson, Stephen C. (1979): «Activity Types and Language», Linguistics 17, 365399.

LEWIS, David (1979): «Scorekeeping in a Language Game», Journal of Philosophical Logic 8, 339-359.

Lyons, John (1977): Semantics, Cambridge: Cambridge University Press.

Martín Zorraquino, María Antonia y José Portolés LÁZARo (1999): «Los marcadores del discurso». En Ignacio Bosque y Violeta Demonte (dirs.), Gramática descriptiva de la lengua española, Madrid: Espasa-Calpe, 4051-4213.

Moreno Fernández, Francisco (2005): «Corpus para el estudio del español en su variación geográfica y social: el corpus PRESEEA», Oralia 8, 123-140.

Moya Corral, Juan Antonio y Juan Andrés Villena Ponsoda (2005): «Corpus para el estudio de las hablas andaluzas II: los corpus de Málaga, Granada y Jaén», Oralia 8, 189-212.

NuYTs, Jan (2001a): Epistemic Modality, Language, and Conceptualization, Ámsterdam y Filadelfia: John Benjamins.

- (2001b): «Subjectivity as an Evidential Dimension in Epistemic Modal Expressions», Journal of Pragmatics 33, 383-400.

- (2012): «Notions of (Inter) subjectivity», English Text Construction 5/1, 53-76.

Padilla, Xose A. (2005): Pragmática del orden de palabras, Alicante: Universidad de Alicante.

Pérez Saldanya, Manel (2008): «Es que». En A. Briz, S. Pons y J. Portolés (coords.), Diccionario de partículas discursivas del español. En línea: <www.dpde.es $>$.

— y Vicent SALVAdor (2014): «Oraciones subordinadas concesivas». En Concepción Company (dir.), Sintaxis histórica de la lengua española. Tercera parte: Adverbios, preposiciones y conjunciones. Relaciones interoracionales, México: FCE/UNAM, 3697-3840.

Peterson, Tyler (2013): «Rethinking Mirativity: The Expression and Implication of Surprise», Ms. University of Toronto. <http://semanticsarchive.net>.

Porroche, Margarita (1998): «Sobre algunos usos de que, si y es que como marcadores discursivos». En María Antonia Martín Zorraquino y Estrella Montolío (eds.), Marcadores del discurso, Madrid: Arco/Libros, 229-242.

Portolés, José (1998): «El concepto de suficiencia argumentativa», Signo y Seña 9, 201-224.

- (2004): Pragmática para hispanistas, Madrid: Síntesis.

PrINCE, Ellen (1981): «Toward a New Taxonomy of Given-New Information». En Peter Cole (ed.), Radical Pragmatics, Nueva York: Academic Press, 223-255.

Real Academia Española y Asociación de Academias de la Lengua Española [RAE/AALE] (2009): Nueva gramática de la lengua española. Morfología y sintaxis, Madrid: Espasa-Calpe.

- y - (2011): Nueva gramática de la lengua española. Fonética y fonología, Madrid: Espasa-Calpe.

Reig Alamillo, Assela (2011): «The Pragmatic Meaning of the Spanish Construction lo que pasa es que», Journal of Pragmatics 43, 1435-1450. 
Rodríguez Puente, Paula (2018): «En busca de lo hablado en lo escrito en los corpus diacrónicos del español: una comparativa con los corpus anglosajones», e-Scripta Romanica 5, 89-127.

Rodríguez RosiQue, Susana (2008): Pragmática y gramática. Condicionales concesivas en español, Frankfurt am Main: Peter Lang.

- (2018): «From Time to Surprise: The Case of será posible in Spanish». En Sylvie Hancil, Tine Breban y José Vicente Lozano (eds.), New Trends in Grammaticalization and Language Change, Ámsterdam y Filadelfia: John Benjamins, 185205.

- (2019a): El futuro en español. Tiempo, conocimiento, interacción, Berlín: Peter Lang.

- (2019b): «GestINF: Desafíos de un proyecto basado en el conocimiento compartido». En Adrián Cabedo y Antonio Hidalgo (eds.), Pragmática del español hablado, Valencia: Universidad de Valencia, 69-82.

- y Jordi Antolí Martínez (2020): «El conocimiento compartido y su reflejo lingüístico: Un viaje de ida y vuelta». En Susana Rodríguez Rosique y Jordi Antolí Martínez (eds.), El conocimiento compartido. Entre la pragmática y la gramática, Berlín: De Gruyter, 1-20.

Rojo, Guillermo (2016): «Los corpus textuales del español». En Javier GutiérrezRexach (ed.), Enciclopedia lingüistica hispánica, Londres: Routledge, 285-296.

Ruiz GuRILlo, Leonor y Salvador PONS Bordería (2005): «Corpus para el estudio de la conversación coloquial: el corpus Val.Es.Co. (Valencia Español Coloquial)», Oralia 8, 243-264.

Schwenter, Scott A. (1999): «Two Types of Scalar Particles: Evidence from Spanish». En Javier Gutiérrez-Rexach y Fernando Martínez Gil (eds.), Advances in Hispanic Linguistics, 2, Somerville: Cascadilla Press, 546-561.

- (2001): «Additive Particles and the Constructions of Context», Quaderns de Filologia. Estudis Linguistics 6, 245-262.

- (2003): "No and tampoco, a Pragmatic Distinction in Spanish Negation», Journal of Pragmatics 35/7, 99-130.

Stalnaker, Robert C. (1978): «Assertion». En Peter Cole (ed.), Syntax and semantics 9: Pragmatics, Nueva York: Academic Press, 315-332.

Traugott, Elizabeth C. (2010): «(Inter)subjectivity and (Inter)subjectification: A Reassessment». En Kristin Davidse, Lieven Vandelanotte y Hubert Cuyckens (eds.), Subjectification, Intersubjectification and Grammaticalization, Berlín y Nueva York: Walter de Gruyter, 29-71.

- y Graeme Trousdale (2013): Constructionalization and Constructional Changes, Oxford: Oxford University Press.

VILA, María Rosa (2001): Corpus del español conversacional de Barcelona y su área metropolitana, Barcelona: Universidad de Barcelona.

Willet, Thomas (1988): «A Cross-linguistic Survey of the Grammaticization of Evidentiality», Studies in Language 12, 51-97.

Zubizarreta, María Luisa (1999): «Tema y foco». En Ignacio Bosque y Violeta Demonte (dirs.), Gramática descriptiva de la lengua española, Madrid: EspasaCalpe, 4215-4233. 